\title{
Some Remarks on the Individual Contribution to Climate Change
}

\author{
Andreas Oberheitmann ${ }^{1,2,3}$ \\ ${ }^{1}$ Research Center for International Environmental Policy, School of Environment, Tsinghua University, Beijing, China \\ ${ }^{2}$ Rheinisch Westfälisches Institut für Wirtschaftsforschung, Essen, Germany \\ ${ }^{3}$ Jiangnan University, Wuxi, China \\ Email: oberheitmann@tsinghua.edu.cn
}

Received January 31, 2013; revised March 3, 2013; accepted April 7, 2013

Copyright (C) 2013 Andreas Oberheitmann. This is an open access article distributed under the Creative Commons Attribution License, which permits unrestricted use, distribution, and reproduction in any medium, provided the original work is properly cited.

\begin{abstract}
Climate change is one of the most important challenges of the $21^{\text {st }}$ Century. As greenhouse gas concentration of the atmosphere has reached the 400ppm threshold of a $2^{\circ} \mathrm{C}$ global warming on 9 May 2013 and irreversible tipping points of the climatic system at some point of time have got even more likely, the question of the individual contribution to climate change becomes more and more virulent. For a long time, the absorption capacity of the environment has been regarded as limitless, and based on this perception, the economic entities used the environment for hundreds of years without constraints. Today, with progress of scientific knowledge, we are now aware of the possible negative impacts of climate change to environmental, economic and social systems on Earth. This awareness, however, did not lead to a significant change of individual behavior, because the perceived individual contribution to both the anthropogenic cause of climate change and its mitigation is still regarded as marginal. To encounter this misperception or "diffusion of environmental responsibility", this article presents an alternative calculation of the individual contribution to climate change taking the incremental approach to a tipping point or a $2^{\circ} \mathrm{C}$ global warming threshold into account.
\end{abstract}

Keywords: Climate Change; Individual Contribution; Tragedy of the Commons; Diffusion of Environmental Responsibility; Tipping Points; $2^{\circ} \mathrm{C}$ Global Warming

\section{Introduction}

For a long time, the Earth's absorption capacity for pollutants and greenhouse gases (GHGs) such as carbon dioxide $\left(\mathrm{CO}_{2}\right)$ had been regarded as almost limitless. Hence, the individual contribution to environmental degradation was neglected and the environment has not been included as a limiting production factor for goods and services. In the $18^{\text {th }}$ Century, Malthus [1] stated that population is growing quicker than agricultural production leading to a limit to economic growth and finally to famine and disease. In 1972, the publication of the Club of Rome ("The limits to growth") [2] focused on world population, industrialization, pollution, food production and especially resource depletion as possible limits to growth. Nowadays, coping with the negative impacts of climate change and recognizing the existence of anthropogenic greenhouse gas emissions, "the limits to growth "actually have to be defined from an ecological view rather than as from the perspective of resource availability constraints.
The perception of the individual contribution to the generation of climate change, however, is still an important factor both for a) the increasing global contribution of individuals to climate change and $b$ ) also for the lack of sufficient individual contribution to its mitigation. Hardin [3] described this phenomenon with a pasture shared by local herders, called a commons. The herders are assumed to wish to maximize their yield, and so will increase their herd size whenever possible. The utility of each additional animal has two components, a positive and a negative. Tragically, the division of these costs and benefits is unequal: the individual herder gains all of the advantage, but the disadvantage of the incremental degradation of the pasture is shared among all herders using the pasture. Consequently, for an individual herder the rational course of action is to continue to add additional animals to his herd. However, since all herders reach the same rational conclusion, overgrazing with immediate losses occurs, and degradation of the pasture may be its long-term fate [3].

As for the individual utilization of fossil fuels and re- 
lated costs of climate change it is quite similar. The single economic entity gets the full utility from using fossil fuels, e.g. by driving a new fossil fuelled car, but the costs of climate change are shared globally. This effect is the stronger

- the smaller the perceived individual contribution to climate change and

- the larger the absorption capacity of the atmosphere and thus the smaller the probability and costs of climate change are perceived by the individual economic entity. This phenomenon could be described my by the term "diffusion of environmental responsibility", inspired by the socio-psychological phenomenon of "diffusion of responsibility" whereby a person is less likely to take responsibility for action or inaction in emergencies the more others are present [4].

In fact, the costs of climate change are increasing, maybe even per capita with a growing world population, as greenhouse gases are continuously piling up in the atmosphere. But the marginal cost of climate change impact still does not outweigh the marginal utility from contributing to climate change [5]. This may be only the case, if one or more of so-called tipping points are reached and climate change costs increase tremendously, literally from one day to the other. But then, it may be too late.

On 9 May 2013, for the first time since measurements began in 1958, the daily mean concentration of carbon dioxide in the atmosphere of Mauna Loa, Hawaii, surpassed 400 parts per million (ppm) [6]. A 400ppm $\mathrm{CO}_{2}$-concentration of the atmosphere is seen as the lower boundary for reaching a global warming of $2^{\circ} \mathrm{C}$ with a low probability. Currently, the atmospheric $\mathrm{CO}_{2}$-contentration is increasing by about $2 \mathrm{ppm}$ per annum.

If climate change further continues, these tippingpoints can be reached, at which the climate abruptly and irreversibly reacts [7]. However, when these points will exactly be reached, it is still uncertain. The tipping point for an ice-free Arctic in the summer could already be very close. Global warming in connection with cutting rain forest could also lead to a tipping point, where the ecological system rain forest drains and completely breaks down finally. This would have substantial effects for the global climate, since less and less carbon dioxide can be absorbed and escapes into the atmosphere. Other tipping points exist approximately with the acidification of the oceans or to begin of the monsoon in India [8].

This article aims at presenting an alternative calculation of the individual contribution to climate change taking the uncertainty of reaching a tipping point or a threshold of $\mathrm{CO}_{2}$-concentration in the atmosphere for a $2^{\circ} \mathrm{C}$ global warming into account (Section 2). Section 3 summarizes the article.

\section{Calculation of the Individual Contribution to Climate Change}

The individual contribution to climate change has been calculated in different ways (e.g. Lenzen, 1997 [9]; Höhne and Blok, 2005 [10]). The simplest approach was to calculate per-capita emissions of global greenhouse gases (Equation (1)):

$$
B_{t}=\frac{G H G_{t}}{P O P_{t}}
$$

with:

$B_{t}=$ Individual contribution to climate change in year $t$ (tons $\mathrm{CO}_{2 \mathrm{eq}}$ );

$G H G_{t}=$ Global (net) greenhouse gas emissions in year $t$ (tons $\mathrm{CO}_{2 \mathrm{eq}}$ );

$\mathrm{POP}_{t}=$ World population in year $t$ (individuals).

$G H G_{t}$ are net emissions in the sense that they include a small share of greenhouse gas emissions which have been naturally absorbed by the climate system and being emitted about 100 years and more ago.

The concept of calculating per-capita greenhouse gas emissions is only calculating present world greenhouse gas emissions in one year relative to its world population. This concept, however, does not take into account the different contributions of different countries to climate change and neglects the fact that climate change is a phenomenon which is based on the accumulation of greenhouse gases in the atmosphere. Hence, taking the principle of "common, but differentiated responsibility" [11] into account, Equation (2) better states:

$$
B_{m, t}=\frac{\frac{G H G_{m, t}}{P O P_{m, t}}}{\sum_{t=1750}^{n} \sum_{m=1}^{j} G H G_{m, t}}
$$

with:

$B_{m, t}=$ Individual contribution to climate change in year $t$ and country $m$ (tons $\mathrm{CO}_{2 \mathrm{eq}}$ );

$G H G_{m, t}=$ (net) Greenhouse gas emissions in year $t$ and country $m$ (tons $\mathrm{CO}_{2 \mathrm{eq}}$ );

$P O P_{m, t}=$ World population in year $t$ and country $m$ (individuals);

As an example, Table 1 shows the development of cumulated $\mathrm{CO}_{2}$-emissions per capita in the world ad selected countries according to the three GDP-growth scenarios (BAU, HIGH, LOW) applied in Oberheitmann (2010) [12]. The average per-capita emissions allowed for reaching the $400 \mathrm{ppm}$ resp. $450 \mathrm{ppm}$ are shown at the bottom of the table in blue color.

If, as a normative postulate, every human being on Earth shall have the same budget of cumulated emissions of year $t$, the calculation should be as shown in Equation (3). 
Table 1. Development of cumulated $\mathrm{CO}_{2}$-emissions per capita $^{1}$ in the world (2010-2050, in $\left.t \mathrm{CO}_{2, \mathrm{cum}}\right)$.

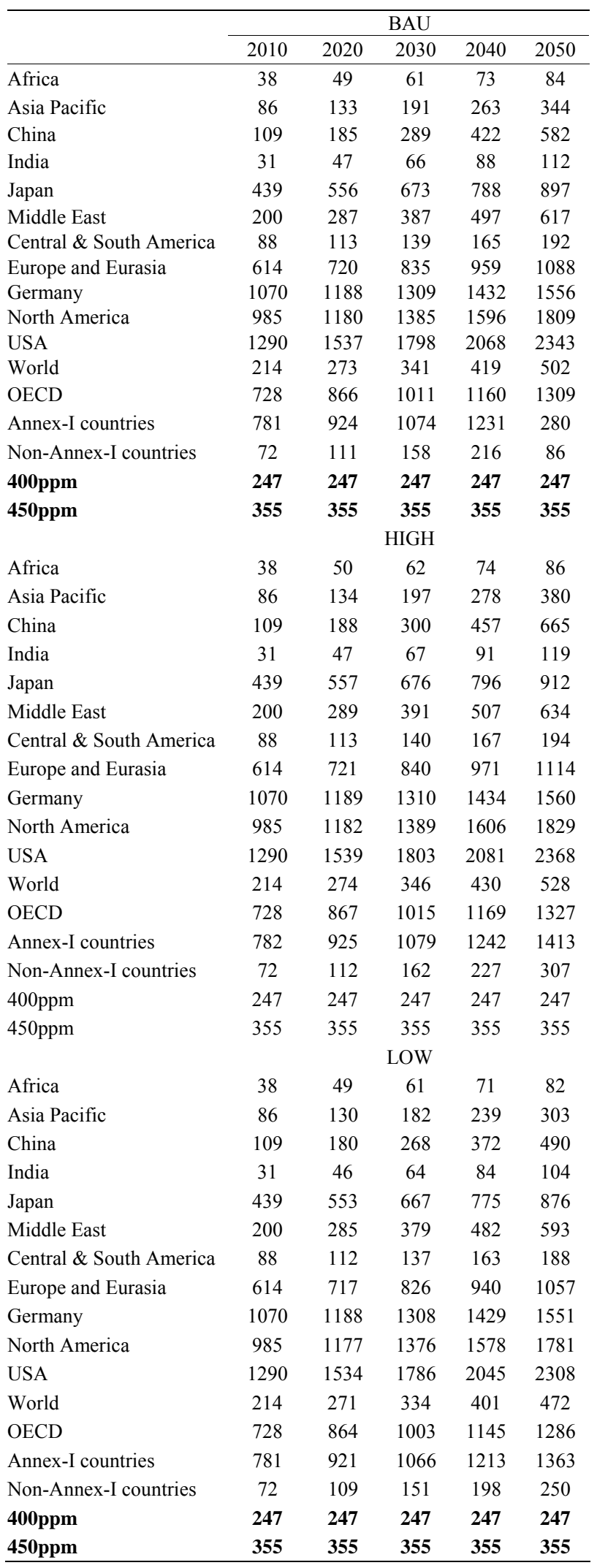

Source [12]; ${ }^{1}$ Population 2007.

$$
B_{m, t}=\frac{\sum_{m=1}^{j}\left(\frac{G H G_{m, t}}{P O P_{m, t}}\right)}{\sum_{t=1750}^{n} \sum_{m=1}^{j} G H G_{m, t}}
$$

with:

$B_{m, t}=$ Individual contribution to climate change in year $t$ and country $m$ (tons $\mathrm{CO}_{2 \mathrm{eq}}$ );

$G H G_{m, t}=$ (net) Greenhouse gas emissions in year $t$ and country $m$ (tons $\mathrm{CO}_{2 \mathrm{eq}}$ );

$P O P_{m, t}=$ World population in year $t$ and country $m$ (individuals);

This calculation, however, still does not lead to a sufficient perception of the individual contribution to climate change as there is no indication of a limitation of greenhouse gases due to the possible impacts of climate change. It still creates the impression that the individual contribution to climate change is marginal.

Equation (4) takes the individual contribution to a possible impact on climate change into account:

$$
B_{m, t}=\frac{\sum_{m=1}^{j}\left(\frac{G H G_{m, t}}{P O P_{m, t}}\right)}{\frac{1}{\alpha} \cdot G H G_{\text {cum }, \text { max }}-\sum_{t=1750}^{n} \sum_{m=1}^{j} G H G_{m, t}}
$$

with:

$B_{m, t}=$ Individual contribution to climate change (tons $\left.\mathrm{CO}_{2 \mathrm{eq}}\right)$;

$G H G_{m, t}=$ (net) Greenhouse gas emissions year $t$ (tons $\left.\mathrm{CO}_{2 \mathrm{eq}}\right)$;

$P O P_{m, t}=$ World population year $t$ (individuals);

$\alpha=$ assumed probability to reach a tipping point (\%);

$G H G_{\text {cum }, \max }=$ Maximum cumulated $\mathrm{CO}_{2}$-emissions to reach a tipping point (tons $\mathrm{CO}_{2 \mathrm{eq}}$ );

It calculates the individual contribution to climate change based on the decreasing difference to an uncertain reach of a certain tipping point. The incremental per capita emissions in year $t$ lead to a closer and closer approach of the tipping point threshold. Which amount of cumulated greenhouse gas emissions will trigger the tipping point, however, is uncertain. This uncertainty is covered by the assumed probability $(1 / \alpha)$. Ex post, the individual contribution to reach this threshold increases as every additional unit of GHG-emission is leading the climate system closer to the tipping point. The last unit of GHG emission reaching the tipping point is the "drop of water which causes the bucket to overflow".

The question, however, is still open, whether ex ante, the impact of an incremental unit of GHG-emission over time is to be perceived as equal. As long as the tipping point is not reached, it is basically perceived as equal, because every unit of GHG-emission contributes to reaching the (unknown) tipping point regardless the time of its emission. Only, if the tipping point is reached, it 
becomes unequal, but then it is too late. This is also a learning from the human interference in the eco-system of the Easter Islands [5].

The same applies for reaching the threshold of a $2{ }^{\circ} \mathrm{C}$ increase of global mean temperature, which is commonly accepted as a political goal of international climate policy, e.g. by the EU [13]. According to current scientific knowledge, the $2{ }^{\circ} \mathrm{C}$ threshold for greenhouse gas concentration in the atmosphere is about 400-450ppm [14]. Figure 1 shows the ex-post development of the individual contribution to climate change based on the calculations of cumulated global GHG-emissions in Oberheitmann (2010) for the 400ppm threshold to keep global warming below $2^{\circ} \mathrm{C}$ of about 1.9 trillion tons of cumulated GHG-emissions [12].

Figure 2 shows the relation between global cumulated GHG-emissions and $\mathrm{CO}_{2}$-concentration in the atmos- phere indicating the threshold for $400 \mathrm{ppm}$ of about 1.9 trillion tons.

In this article, an optimistic $90 \%$ probability $\alpha$ for keeping the global mean temperature rise below $2{ }^{\circ} \mathrm{C}$ relative to pre-industrial levels is assumed [15]. As shown in Figure 1, in 1950, the individual contribution to climate change was still marginal. By about 1964, factor B started to increase significantly and will mathematically converge to infinity during the year 2016 .

This ex-post depiction of the individual contribution to climate change does not solve the problem that ex ante the location of the threshold for reaching the $2^{\circ} \mathrm{C}$ target is unknown or where the exact location of a tipping point of the climatic systems is. However, it may contribute to improve the readiness of individuals and other economic entities to rethink their environmental behavior before certain thresholds for irreversible changes in the climate
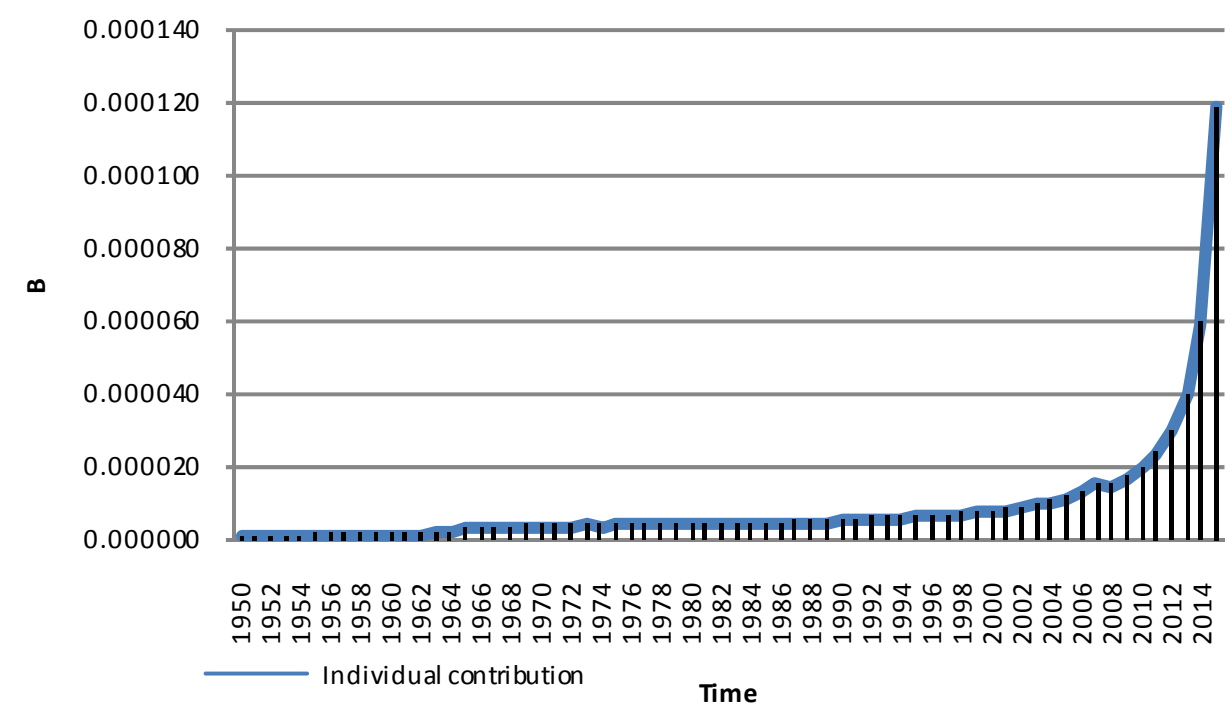

Figure 1. Development of individual contribution to climate change (ex post, 1950-2030). Source: [12], own calculation.

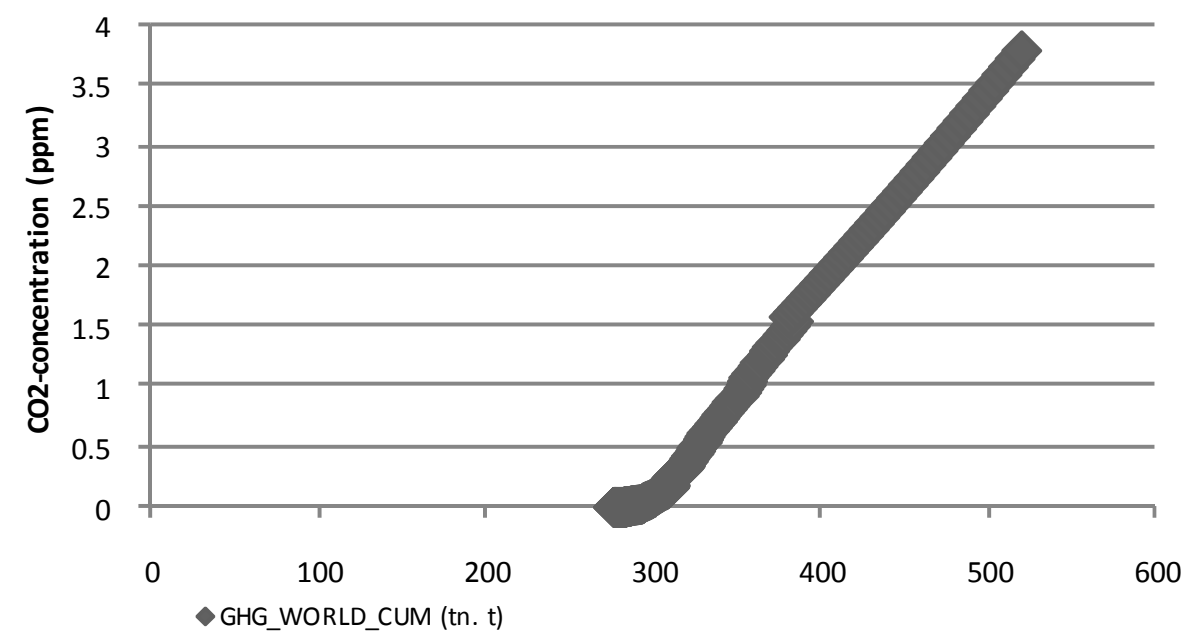

Figure 2. Cumulated GHG-emissions and $\mathrm{CO}_{2}$-concentration (ppm). Source: [12]. 
system are reached.

\section{Summary}

One dilemma of climate change is that the perceived individual contribution to both causing climate change and taking part in mitigating this process seems only marginal. On the one hand, this leads to an overuse of the absorption capacity of the climatic system, on the other hand it causes a lack of individual mitigation action, e.g. energy saving.

Taking into account the incremental individual contribution to getting closer to a $2^{\circ} \mathrm{C}$ global warming or pos-sible irreversible tipping points of the climatic system, the presented ex-post calculation of this factor B may increase the awareness of the individual responsibility for climate change.

\section{REFERENCES}

[1] T. R. Malthus, "An Essay on the Principle of Population as It Affects the Future Improvement of Society, with Remarks on the Speculations of Mr. Godwin, M. Condorcet, and Other Writers," J. Johnson, London, 1798

[2] D. H. Meadows, D. L. Meadows, J. Randers and W. W. Behrens III, "The Limits to Growth," New York, 1972.

[3] G. Hardin, "The Tragedy of the Commons," Science, Vol. 162, No. 3859, 1968, pp. 1243-1248. doi:10.1126/science.162.3859.1243

[4] J. M. Darley and B. Latané, "Bystander Intervention in Emergencies: Diffusion of Responsibility," Journal of Personality and Social Psychology, Vol. 8, No. 4, 1968, pp. 377-383. doi:10.1037/h0025589

[5] A. Oberheitmann, "Economic Growth and a Low Carbon Economy-Does the Earth Suffer from an Easter Island Syndrome?" Low Carbon Economy, Vol. 2, No. 4, 2011 , pp. 200-204. doi:10.4236/lce.2011.24024

[6] NOAA, "Carbon Dioxide at NOAA's Mauna Loa Observatory reaches new milestone: Tops 400ppm," 2013. http://researchmatters.noaa.gov/news/Pages/CarbonDioxi deatMaunaLoareaches400ppm.aspx

[7] R. K. Pachauri and A. Reisinger, "Climate Change 2007. Synthesis Report. Contribution of Working Groups I, II and III to the 4th Assessment Report of the Intergovernmental Panel on Climate Change," IPCC, Geneva, 2007.

[8] T. M. Lenton, H. Held, E. Kriegler, J. W. Hall, W. Lucht, S. Rahmstorf and H. J. Schellnhuber, "Tipping Elements in the Earth's Climate System," Proceedings of the National Academy of Sciences, Vol. 105, No. 6, 2008, pp. 1786-1793. doi:10.1073/pnas.0705414105

[9] M. Lenzen, "Individual Responsibility and Climate Change, Environmental Justice Conference," The University of Melbourne, Mimeo, 1997.

[10] N. Höhne and K. Blok, "Calculating Historical Contributions to Climate Change-Discussing the 'Brazilian Proposal'," Climatic Change, Vol. 71, No. 1-2, 2005, pp 141173. doi:10.1007/s10584-005-5929-9

[11] Z. W. Yang, "The Right to Carbon Emission: A New Right to Development-A Chinese Perspective," American Journal of Climate Change, Vol. 1, No. 2, 2012, pp. 108-116. doi:10.4236/ajcc.2012.12009

[12] A. Oberheitmann, "A New Post-Kyoto Climate Regime Based on Per-Capita Cumulative Emissions Rights-Rationale, Architecture and Quantitative Assessment of the Implication for the $\mathrm{CO}_{2}$-Emissions from China, India and the Annex-I Countries by 2050," Mitigation and Adaptation Strategies for Global Change, Vol. 15, No. 2, 2010, pp. 137-168. doi:10.1007/s11027-009-9207-4

[13] European Commission, "Limiting Global Climate Change to 2 Degrees Celsius - The Way Ahead for 2020 and Beyond," Communication of the Commission to the Council, the European Parliament, the European Economic and Social Committee and the Committees of the Regions, $\operatorname{COM}(2007) 2$ final, Brussels, 10.1.2007.

http://eur-lex.europa.eu/LexUriServ/LexUriServ.do?uri= COM:2007:0002:FIN:EN:PDF

[14] M. Meinshausen, N. Meinshausen, W. Hare, S. Raper, K. Frieler, R. Knutti, D. Frame and M. Allen, "Greenhouse Gas Emission Targets for Limiting Global Warming to $2{ }^{\circ}$ C," Nature, Vol. 458, 2009, pp. 1158-1163. doi:10.1038/nature08017

[15] Climate Change Expert Group EG Science, "The $2^{\circ} \mathrm{C}$ target-Background on Impacts, Emission Pathways, Mitigation Options and Costs: Information Reference Document," Brussels, 2008.

http://ec.europa.eu/clima/policies/international/negotiatio ns/future/docs/brochure_2c_en.pdf 